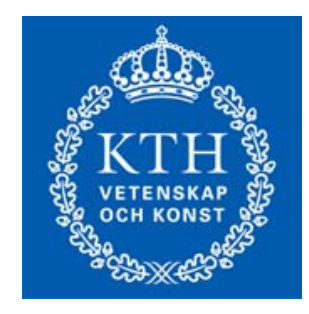

\title{
The effect of rent regulations and contract structure on renovation: A theoretical analysis of the Swedish system
}

Hans Lind

Working Paper 2014:10

Section for Building and Real Estate Economics Department of Real Estate and Construction Management

Centre for Banking and Finance (Cefin)

School of Architecture and the Built Environment

Royal Institute of Technology 


\title{
The effect of rent regulations and contract structure on renovation: A theoretical analysis of the Swedish system
}

\author{
Hans Lind \\ Department of Real Estate and Construction Management \\ $\mathrm{KTH}$ - Royal Institute of Technology \\ 10044 Stockholm, Sweden \\ E mail hans.lind@abe.kth.se
}

\begin{abstract}
The standard view is that rent regulation leads to reduced maintenance as the landlord will be able to find tenants at the regulated rent even if the level of maintenance is low. In this article it is shown that the rent regulation system in Sweden interacts with a contract structure where the rent is allowed to increase only if the standard of the apartment is raised compared to when the apartment was new. Ordinary maintenance is included in the rent, and the rent is therefore not allowed to increase when such maintenance is carried out. It is shown that when there is a housing shortage this system creates economic incentives for increasing the standard of the apartment even if this reduces total welfare. The result can be that quality is increased more than in a market system, and that it can increase gentrification compared to such a system. Policy proposals are also presented.
\end{abstract}

Keywords: rent regulation, maintenance, renovation, Sweden, gentrification 


\section{Introduction}

The Million Homes program was carried out in Sweden 40-50 years ago. During the period 1960-1975 more than one million housing units were built. Around $50 \%$ of these were multifamily rental housing, of which the majority was owned by municipal housing companies.

Renovation of this large housing stock is now high on the agenda in Sweden and renovation is analyzed from a number of different perspectives. How the renovation should be financed is e.g. discussed in SABO (2009). The possibility to combine renovation with energy efficiency measures is analyzed in Högberg (2011). Part of the suburban million home program areas have high levels of unemployment and are dominated by first and second generation immigrants. This also raises the question if renovation programs can be combined with other measures to improve the social situation and reduce segregation (see e.g. Lind \& Lundström 2008). The profitability of various management and renovation strategies from a company perspective is discussed in Blomé (2011) and Blomé (2013). Why neglecting maintenance can be profitable for certain actors is analysed by Blomé and Lind (2012). The papers by Blomé also touch upon the issue of how the rent setting system affect profitability. How the rent regulation system affects the incentives for energy efficiency investments in analyzed in Lind (2012).

The purpose of this theoretical study is to analyze how the rent regulation system affects the incentives for maintaining and renovating multifamily rental housing. A stylized version of the Swedish system is described in section 4. There it is shown that there is a close link between the rent regulation system and certain general features of the Swedish rental contracts and an analysis of the effect of these contract features are therefore also included in the article.

The structure of the paper is as follows. In the Methods section the motive for a theoretical study is presented and the general structure of the comparisons made are presented. Section 3 presents earlier studies of determinants of maintenance in a competitive market and studies on the effects of rent regulation on maintenance. The stylized picture of the Swedish rental contracts and the rent regulation system are presented in section 4 . The general effects of the contract structure are analyzed in section 5 and the effects of the rent regulation is analyzed in section 6 . Even if the focus in this study is on the incentives created by the rent regulation system, and not primarily on income distribution and gentrification issues, the results are looked at from these perspective in section 7. Policy implications can be found in section 8 and concluding reflections in section 9 . 


\section{Method}

This study uses a deductive method and focus on what a rational profit maximizing company would do in different institutional environments. The description of the institutional environment is based on a number of studies concerning the Swedish system of rent regulation (see Elsinga \& Lind,2013, for further references) and also on discussions with actors on the market.

The Swedish system of rent regulation is a decentralized system based on local collective bargaining and therefore there can be differences in the details about what happens to the rent level when a building is renovated. The institutional assumptions made in the article should therefore be seen as a stylized version of the institutional framework and not necessarily correct in all municipalities. The point of reference is how actors would behave in a competitive market as described in section 4 .

Several case-studies have been carried out concerning what happens when Million Homes Program areas are renovated, e.g. Karlsson (2013), Lind et al (2014) and Mezgebu (2014). One way to go beyond these case studies is to look closer at the incentives created by the underlying regulatory system and that is the aim of the current study. One purpose with a more detailed theoretical analysis is also to formulate testable hypotheses that can be the starting point for more systematic empirical studies.

\section{Earlier studies of the effects of rent regulation on maintenance}

\subsection{Determinants of maintenance in a competitive market}

As mentioned above, when effects of rent regulation is analyzed it must be compared to something and the usual reference point is how maintenance and renovation would be determined on a competitive market without any specific regulations. It is therefore natural to start with two important works on models of housing maintenance in an unregulated market: Arnott, Davidson and Pine (1983, 1986).

In both works the problem is analyzed with optimization models that includes a number of parameters. The models include both construction cost and the optimal length of the buildings life, aspects that are not so relevant for the question that is at the center of this article. Both models can be seen as filtering models where the quality of the building- and the rent - falls over time, but where this process can be slowed down by maintenance expenditure. The article from 1986 also includes spatial aspects of the problems and the difference between maintenance strategies in different locations. The article from 1983 also discuss rehabilitation that is defined as discontinuous measures that increases housing quality. This distinction will be returned to in section 4 below. 
The remaining important variables in their models are the maintenance cost and the effect on the net rent, which can be disaggregated into the effect on the gross rent and on the operating costs. This means that there are two reasons to invest in maintenance and that is:

- Rents can be increased when maintenance increase the quality of the apartment.

- Operating costs can be reduced when there is investment in the technical systems.

In practice these consequences often occur simultaneously and the effect of maintenance can then be simplified into saying that it will increase net rent.

In order to determine whether a building will be maintained or not, a simple investment analysis can be carried out, and this is implicit in the models above. In the investment analysis the maintenance expenditure is compared to the net present value of the increase in the net rent discounted with the rate of return demanded by the investor.

In the analysis of what happens on a competitive market it is assumed that there is no tenant protection and that the landlord can carry out maintenance measures and increase the rent at any time. Short term rental contracts are implicitly assumed.

The main contributions of Arnott, Davidson \& Pine (1983) are described as follows:

In this paper we investigate the issue of change in housing quality under more general assumptions. Instead of assuming that the structure is doomed to deteriorate, we analyse the conditions under which deterioration is profit-maximizing for a representative landlord-builder in a stationary-state economy. Will he keep his building at a constant quality, as Henderson argues? Will he continually downgrade, as Sweeney and Ohls assume? Or are both of these behaviours, and perhaps others which include upgrading and rehabilitation, possible? ( $p$ 468)

Arnott, Davidson \& Pine (1986) they summarize the contribution as follows:

The main results of our analysis are summarized below: (a) Structural density decreases with distance from the city center. (b) If there is any housing which is maintained at constant quality, it is located around the city center. (c) Among housing units that are from time to time demolished and rebuilt, demolition quality rises and maintenance (quality fixed) falls as distance from the city center increases. (d) In a stationary state in which the quality composition of the housing stock at each location is constant, there is a particular pattern to the income distribution by location. At locations in which housing is maintained at constant quality, there are only high and middle income households. ( $p$ 190-191) 


\subsection{Studies of the effect of rent regulation on maintenance}

Olsen (1988) starts with describing the mainstream view of the effect on housing maintenance of rent regulation and according to this view the rent regulation will lead to less maintenance and lower quality. The logic behind this view is simple: If there is a ceiling on the rent level and there is a queue of tenants, then the landlord can reduce maintenance and still find a tenant. If maintenance does not lead to higher rent levels then it is less profitable to maintain and maintenance expenditure is reduced. Maintenance focusing only on reduced operating costs will be carried on in the same way as on a competitive market.

Olsen is very critical of this simplified view and focus on two counterarguments. The first is that rent regulation systems often are combined with tenant protection and then it might be rational for the tenants to do some of the maintenance on their own account. This is shown in e.g. Malpezzi (1986). The second critique is that in many actual rent regulation systems it is possible to increase the rent level when the quality of the apartment is increased. The effect of rent regulation on maintenance would then be determined by the details of the design of the rent regulation systems, and it could even be possible that apartments are maintained/renovated to a higher degree with rent regulation that without. As will be shown below this can happen in the Swedish system.

In a recent study Arnott \& Shevyakhova (2014) focus on "tenancy rent control" where the rent is controlled during a tenancy, but where the rent can be set at market level when an apartment is vacant. They show that if the landlord can commit to a certain level of maintenance, then this rent regulation system has no effect on maintenance. As the level of maintenance will be known when the contract is entered into, and be reflected in the rent level agreed when the contract is entered into, all maintenance that is profitable in the competitive market will also be profitable under this rent regulation system. If the landlord cannot commit to a certain maintenance level, then the result is typically that there is too little maintenance during the contract period, just as in the standard model. When the tenant has moved in and signed the contract, the incentive to keep up maintenance will be low.

\section{Contract structure and rent regulation in Sweden}

\subsection{Two fundamental concepts}

In order to understand the Swedish contract structure a certain conceptual system needs to be explained. In the Swedish terminology (see Lind \& Muyingo 2012) maintenance is defined as measures that restores the original quality of the building/apartment. Examples of maintenance in this sense is repainting, replacing old pipes with new ones, etc. If there is an increase in the quality of the apartment, compared to when it was new, then it is called an investment and an increase in the standard of the apartment. Such an increase can e.g. 
mean that plastic floors are replaced by wooden floors, plastic walls and floors in the bathroom is replaced by tiles and if more advanced ventilation systems are installed.

As underlined in Lind \& Muyingo (2012) both of these concepts can from a theoretical perspective be seen as investments, as they both are measures that affect the future cashflow and the value of the building. In that article it is therefore questioned whether the concept of maintenance really is needed, but as the distinction between maintenance and investment is central for the design of the Swedish rental contracts and the rent regulation system there concepts will be used here.

\subsection{Contract structure}

The rent for an apartment in the Swedish system is not determined by the current condition of the apartment. The contract includes the right to get regular maintenance of the interior of the apartment and the building without an increase in the rent when maintenance is carried out. This e.g. concerns repainting, and replacement of worn out appliances. The rent is therefore in theory the same for an apartment that recently was e.g. repainted as for an apartment that is worn down and has not been maintained for many years.

This means that the rent paid is set at a level that shall cover these costs for maintenance. The landlord is only allowed to increase the rent (more than the general increase in the rent - see below) if there are investments that raise the standard of the apartment. This is why the distinction between maintenance and investment is very important in the Swedish system.

How much the rent is allowed to be raised, above the ordinary negotiated rent increases, when there is a standard increased is usually determined by special negotiations between the landlord and the Tenants' Union. It is common with three types of agreements: bathroom agreements, kitchen agreements and agreements concerning total renovations of an apartment (see Karlsson 2013 for some examples of such agreements).

There is a strong tenant protection in Sweden, so the landlord cannot terminate the contract as long as the tenant pays the rent and fulfills the contractual terms. The tenants also have some influence over the renovations that the landlord is allowed to carry out, but in practice the landlord has the final word when it comes to renovations. The details of the legal procedures will however not be discussed in this paper.

\subsection{General features of the rent regulation system in Sweden}

The Swedish rent regulation system is a local collective bargaining system modelled after the collective bargaining system on the labor market. This means that the law does not say 
anything specifically about how the rents should be set; it is up to the parties on the local market to decide.

The analysis below is based on certain stylized observations about how rents actually are set and these can be summarized in the following points.

1. Most years all rents follow the general inflation.

2. The rent level in new construction is set at a level that is close to the market rent. This can also be seen as a cost based rent with market based land prices.

If point 1 and 2 is combined with the observation that construction costs over time have increased more than inflation (see www.scb.se), the result is that older (unrenovated) buildings generally have lower rents than apartments that are built more recently. The age of the building is the most important determinant of the rent level in Sweden, even if the general standard of the apartments have not changed much over time (see Borg \& Song 2014).

3. There are some minor differences in the size of the rent increases in relation to location, where rents might be increased a little more in locations where the gap between the current rent and the marker rent is higher. In general, however, given a certain age of the building, the difference between the actual rent and the market rent are bigger in more attractive locations, e.g. in the central city compared to the suburbs.

Housing construction have been relatively low in Sweden during the last 20 years while housing demand has increased in the bigger cities. 20 years ago the rent level was equal to the market level in many suburban locations, where there at that time still were vacancies. As demand increased while housing construction was low, there are today queues to apartments in almost all areas in the bigger cities. The current rent level is below the market rent level in all areas in larger cities, even if the gap is especially high in older buildings in central locations. In these central areas a large number of apartments have however been transformed to condominiums.

\subsection{Rent increases when a renovation includes an increase in standard}

A crucial assumption when the effects of the Swedish rent regulation system is analyzed concerns how much the rent is allowed to be increased when there is an increase in the standard of the apartment. Several studies (Karlsson 2013, Lind et al 2014, Mezgebu 2014) indicate that possible rent increase when the standard is increased is rather high; considerable more than what is motivated by the cost of these improvements, i.e. the rent increase is higher than the landlords' reservation rent increase. As this is an important assumption in the analysis below it is important to understand why this is the case. Several 
factors can explain why the Tenants' Union accepts such high rent increases for improvement in standards.

\section{1: Bargaining under uncertainty}

The reservation rent of the landlord is not known by the Tenant's Union. The direct cost of the renovation might be possible to estimate with reasonable certainty, but the reservation rent also depend on the rate of return demanded by the landlord and that is not observable by the Tenants' Union. As the landlord never will accept a rent increase below the reservation rent, the result must be that the agreed rent increase always is above the reservation rent increase, sometimes maybe just a little and sometimes more. One can also see the high rent increases as the result of selection bias: only when the Tenant' Union agrees to an increased rent that is above the reservation rent increase of the landlord will there be an agreement, and therefore we should expect to see only such contracts on the market.

\section{2: Increasing real renovation costs and cross subsidization}

Assume that there is no inflation and that a house was built 40 years ago and that the rental contract says that in 40 years there will be a major renovation that lifts the apartment up to the original quality. Assume further that when the house is built the landlord takes a 40 year (real) annuity loan and when this loan expires after 40 years, a new loan is taken to finance the maintenance measures. As the yearly expenditure for the company do not increase when the maintenance is carried out, there is no need to increase the rent level at the time of maintenance.

However, if the make the more realistic assumption (in Sweden) that construction costs have increased in real terms, then the landlord needs to take a larger loan when maintenance is carried out and the current rent will not cover this. If the "reasonable" Tenant's Union realize that it would be problematic for the landlord to "finance" the ordinary maintenance within the current rent level, the Union is willing to accept a rent increase when renovation is carried out.

There can be two motives for the Tenants' Union to structure the rent increase in such a way that the rent increase is low if there are no standard increases, but rather high if there are standard increases. The first is that if the Tenants' Union want to stick with the view that there should be no rent increases for ordinary maintenance they might prefer a contract where there is relatively small rent increases for the "ordinary" maintenance, but more generous rent increases for improvement of the standard. A second motive could be that in some cases the tenant can choose the level of maintenance when the building is renovated 
(see Lind et al 2014 for an example) and then a low rent increase for ordinary maintenance protects the poorer tenants. In order to compensate the landlord for this low rent increase, the landlord is allowed to increase the rent much more than the reservation rent increase when there is a standard increase.

\section{3: Outside option}

If the parties cannot agree on the rent increase when the house is to be renovated, the landlord can go to the Regional rent and tenancies tribunals. The rent system is formally a comparative system and if an apartment is renovated up to a standard that is similar to the standard in the newly constructed apartments, then the landlord is allowed to increase the rent to a level that is similar to the rent in new construction. As this typically is much higher than in the 40-year old apartment that is to be renovated, it will be risky for the Tenant Union to take the matter to court. This favorable outside option for the landlord can also explain why the Tenant's Union agree to a rather high rent increase when the standard of the apartment is increased.

\section{Effects on rents and maintenance of the contract structure}

In this section the focus will be on the effect of having a contract where the right to get maintenance is included in the contract and in the rent paid. The rent will then be the same over time independent of the current quality of the apartment and independent of how long ago the apartment was maintained.

In order to analyze the effect of this, maintenance can be divided into two types, one motivated by reduced operating and maintenance cost and one motivated by higher customer satisfaction (higher market rent). In reality most maintenance measures have both these effects.

The first type will not be directly affected by how rents are set. Investments to reduce energy consumption, or replace leaking pipes, or reduce other operating costs will be profitable at a certain point in time both in the Swedish system and in the market based system where the rent is related to the current quality of the apartment.

The second type of maintenance, e.g. repainting the apartment and replacing old appliances with similar new one, will lead to rent increases in the market based system as the perceived quality of the apartment will be higher. If the contract does not stipulate exactly when these renovations shall be made, there is a clear incentive in the Swedish system for the property owner to postpone maintenance, beyond the point in time where it would have been carried out on the competitive market. This is very similar to the situation analyzed by Arnott \& Shevyakhova (2014) where the landlord cannot credibly commit to a certain maintenance 
policy. Notice however that in the Swedish system it is generally not possible to make maintenance, and increase the rent, when there is a new tenant, so this second type of maintenance could be postponed indefinitely in the Swedish system. The logic is the same as the one described in Lind (2012) where it is pointed out that if rents are not responsive to quality increases, like less draught, then incentives for energy efficiency investment will be lower in the Swedish rent regulation system compared to a competitive market.

The reduction in landlord maintenance could, as Olsen (1988) argues, be replaced by maintenance by the tenant. During the 1990s, when housing subsidies were reduced, the Tenant's Union wanted to restrict rent increases and in some municipalities the new agreement meant that the tenant became responsible for parts of the interior maintenance. It was then still common that the landlord, in areas with lower demand, made improvements in the apartment when the apartment was vacant simply to make the apartment more attractive for "better" tenants (see Ekelid \& Lind 1998).

As mentioned above, many maintenance measures both reduce operating costs and increase quality in the eyes of the tenants. If rents cannot be increased, the incentives for such combined maintenance measures will also be lower with the Swedish type of rental contracts. If the operating cost in the unmaintained building increase over time, the result is that maintenance measures will be carried out later in the Swedish system compared to the competitive case.

If there were no inflation and no cost changes over time, the rent in the Swedish system would be constant over time, even if the quality of the apartment deteriorates over time, up to the point where the maintenance is carried out. In the competitive market rents would fall over time as lower quality reduces demand. Everything else equal, the Swedish system should create queues to recently maintained apartments, and difficulties to find tenants for the unmaintained apartments. This is however currently counteracted by the general effect of the rent regulation system where older apartments have lower rents than newer ones.

Another effect of the contract design and the rent profile is the following. As rents are not reduced when the apartment quality deteriorates over time it follows that there will be no supply of cheap unmaintained apartments in the Swedish market. In a competitive market with filtering (see e.g. Rosenthal 2014) there will always be cheap low quality housing available. A low income household can reduce their housing costs by moving to rental apartments that will be renovated in a few years, and then move to another such apartment when the current one is about to be renovated. This strategy is however not possible with the Swedish system as the rent does not fall when the quality deteriorates.

A further step could be to make a "general equilibrium analysis" and investigate how the contract structure affect the long term supply of rental housing. The contract structure is however only one part of a housing policy complex, where municipal housing companies 
and the rent regulation system is other parts. Empirically isolating the effect of the contract structure on housing supply is therefore in practice very difficult.

A final question is what could be the rationale for the Swedish contract structure. One possible rationale is if there are many long term tenants that stay for decades in the same apartment, and that these tenants have a strong preference for rent smoothing over time and/or high transaction costs. A parallel could be drawn to the literature on wage stickiness where wages are smoothed over the business cycle. Maybe this assumption was more realistic when the contract type was introduced after the Second World War. Today it is however hard to see why tenants who live for a few years in an un-renovated apartment, and then move on, should "subsidize" tenants who move in and live for a few years in a recently maintained apartment.

\section{Rent regulation and quality increasing maintenance measures}

\subsection{Important dimensions}

In order to analyze the effects of rent regulation on a renovation where the standard of the apartment is affected, it is necessary to distinguish a number of cases with different characteristics. Important dimensions are:

1. The gap between the current rent (CR) and the market rent for an un-renovated apartment $(M R U)$. In the rest of the analysis it will be assumed that this gap is rather large. As described in the introduction, this has earlier been the case in older apartments in more central locations in metropolitan area, but the growth of population and low level of housing construction has led to a situation where the gap is large in most of the Million Homes Program areas in the metropolitan areas.

2. The willingness to pay for higher quality among the sitting tenants (WTP). To simplify the discussion it will be assumed that this is equal to the difference between the market rent for an un-renovated apartment and the market rent for a renovated apartment (MRR). Initially it will be assume either that the current tenants stay in the apartment or that all households are identical. In section 7 income distribution and gentrification effects will be discussed.

3. The relation between the landlords reservation rent increase for carrying out a renovation (RRI, related to the cost of the quality improvement) and the allowed rent increase in the rent regulation system (ARI). For reasons discussed in section 4.3 it will be assumed that the allowed rent increase (ARI) is considerably higher than the reservation rent increase (RRI). 


\subsection{Case 1: High willingness to pay for quality increases}

Some of the Million Homes Program stock is located in areas where the tenants have rather high incomes, typically in more central locations. In such an area it can be assumed that the tenant's willingness to pay for the quality increase is higher than the landlords' reservation rent increase: WTP > RRI. From an efficiency perspective the renovation should then be carried out. It is however not certain that both parties will gain by the renovation, as we can identify two different cases:

\section{Case 1.1 WTP > ARI > RRI}

In this case the renovation is sanctioned by the Pareto criterion as everyone will be better off after the renovation. The welfare increase (WTP-RRI) is shared between the parties. Exactly how the increase is shared between the parties depend on the size of ARI in relation to WTP and RRI.

\section{Case 1.2 ARI > WTP > RRI}

In this case the allowed rent increase is higher than the tentants' willingness to pay. It can be assumed that the landlord has no interest in increasing the rent above the market level after the renovation (MRR) so it must be the case that $C R+A R I<M R R$, but it still might be the case that ARI > WTP if CR is below MRU. There has been articles in Swedish media about tenants' protesting against what they call luxury renovations and too high rent increases, but still the tenants stay in the apartment after the renovation. What happens in Case 2 is that the landlord uses the renovation to take some of the consumer surplus created by the rent regulation from the tenants. Notice however that even if the renovation in this case is not sanctioned by the Pareto criterion, it is still motivated from an efficiency perspective as WTP $>$ RRI.

\subsection{Case 2: Low willingness to pay for quality increases}

In this case the relation between the variables are as follows: ARI > RRI > WTP. The typical case here is a suburban area with low-income tenants. In recent years, the market rent also in these areas have been well above the current rent, so there is a potential for rent increases in these areas also.

From an efficiency perspective this renovation with quality increases should not be carried out as WTP is lower than RRI. The renovation is however profitable for the landlord if the rent after renovation is below or at the market rent level ( $C R+A R I \leq M R R)$. In this case the 
only purpose of the renovation is that the landlord can take some of the tenants' consumer surplus created by the rent regulation system.

If the rent level from the beginning had been at the market level this renovation would not have been carried out as RRI > WTP. The landlord would then, just as the tenants, have preferred maintenance measures without any quality increase. This is then an example of a case where rent regulation leads to more maintenance and to higher quality than a competitive market.

\subsection{Further aspects}

It is not known how common these different situations are, and this is an interesting topic for further research even if a number of central variables are difficult to measure, especially WTP and RRI. There are also complications related to the welfare system that affect the outcome in case 2 above. Households that live on social welfare or have housing allowances will get compensation for at least some of the rent increase, and may therefore gain by the renovation even if their WTP with their own money is low. In that case the increased profit for the landlord comes partly from the consumer surplus and partly from the state and municipality that pays housing allowances and social welfare. This also needs to be studied more in detail.

\section{Effects on low income households and gentrification}

If the results presented in earlier sections are looked upon from the perspective of the effects on low income households and on gentrification processes it is necessary first to underline that it is difficult to formulate a credible counterfactual story with assumptions concerning both the market and housing policy. Given this reservation, the results above however indicate the following.

1. The contract form where maintenance is included in the rent has the negative effect that a low rent segment of the housing market disappears. In the short term, there is a crosssubsidization from residents in apartments that has not been maintained in many years to residents in apartments that have recently been maintained. If households with lower income to a larger extent lives in the first type of apartment, then the system on average means that low income households subsidize households with higher incomes. As the queues to the maintained apartments should be longer, and as there should be more competition for these apartments, it would mean that the landlord could choose economically stronger households when there is a vacant recently maintained apartment. 
2. The rent regulation system with rather generous rules for rent increases when there is a quality improvement means, firstly, that a low-rent segment in the market disappears in central locations. If preferences concern both location and quality there should be households with rather low incomes, but with strong locational preferences that should prefer a low-quality apartment in a central location. In equilibrium a certain share of such apartments would exist in the market as the rent gap would stabilize at a level equal to the cost based reservation rent increase. This stock of low-quality apartments in central locations however disappears in the Swedish model, as it is not allowed to increase rent just because demand is high in a certain location. The only way to increase the rent in a centrally located apartment is to raise the quality of the apartment.

Even if the majority of the improvements are efficient, in the sense that WTP is higher than $\mathrm{RRI}$, a certain share of the renovations cannot be rationalized in this way. The result is that after a while all apartments will be renovated and there will be no apartments left for the group with lower incomes but with strong locational preferences. The consequences would then be that in the long run the rent regulation strengthen gentrification processes in central locations in Swedish cities.

In suburban locations similar processes can be expected: In order to be able to increase rents when demand is strong it is necessary to increase quality and in the end the rent will be higher than it would have been if the rent was allowed to increase in response to demand. If the rent was allowed to increase without an increased standard, the inefficient renovation would not be profitable. Here also poorer households would be pushed out of the area in a quicker way than in a competitive market system, everything else equal. This can be compared to the effect of stricter building regulations on homelessness discussed in e.g. O'Flaherty (1998).

\section{Policy implications}

Policy implications can be discussed both from a long-term perspective, where contract forms and housing policy as a whole can be changed, and a short term perspective where a rent regulation system still is in place.

Many of the problems discussed above would be reduced if housing supply increased, especially housing supply designed for groups with somewhat lower incomes. Such an increase in supply would reduce the general rent level and thereby reduce the opportunity to increase the rent in the current stock. The incentive for inefficient quality improvements would be reduced, and there would also be a pressure on landlords to reduce rents in unmaintained apartments as they otherwise would risk vacancies.

In the same way, the incentives for inefficient quality increases would e reduced if current demand would be allowed to play a larger role for the current rent. Weakening the rent 
regulation system would however in the short term lead to higher rents in almost all areas. As argued in a recent policy proposal by an independent expert group (Eklund 2014) weakening the rent regulation system will only be socially acceptable if there is a large increase in housing supply at the same time.

If the focus is only on avoiding inefficient quality increases within the current rent regulation system, then changes in the contract structure could be a first step. Instead of not accepting rent increases when there is "only" ordinary maintenance, and accepting large rent increases when there is a quality increase, the Tenant's Union and the Courts should accept "reasonable" rent increases when there is ordinary maintenance, but not any large rent increases when there is a quality increase, especially in areas where there lives many lowincome households. In that way the rent would to a large degree reflect the current conditions of the apartments, as in a competitive market, and the incentive to inefficient quality increases would be weakened.

\section{Conclusions}

One lesson from this analysis is very much in line with comments from Olsen (1988) and Arnott (1995). The actual consequences of a rent regulation system depend to a large extent depend on details in the regulatory framework, and how it interacts with other housing policy measures. In Sweden, the importance of the distinction between maintenance, defined as restoring the original quality, and investment, defined as improving the quality in relation to the condition when the building was new, is one such factor. As quality increases is a condition for rent increases, this creates incentives for improving the quality when the current rent is below the market level, even if the willingness to pay for this quality increase is low.

The analysis above also shows that current system has several negative effects from the perspective of low income households. One is related to "unmotivated" quality increases described above. Another is that as the rent includes the right to future maintenance, the rent will be relatively higher in un-maintained apartments compared to a short term contract in a competitive market.

The analysis also shows that these problems can be reduced both through moving away from the rent regulation system to a more market determined system, but also through changes within the framework of the current collective bargaining system. Such reforms would mean that the current condition of the apartment plays a larger role for the rent of the apartment and that larger rent increases would be allowed for ordinary maintenance but that only minor extra increases would be allowed when there are quality increases in the apartments. 


\section{References}

Arnott, R. (1995), Time for revisionism on rent control? Journal of Economic PerspectivesVolume 9, Number 1, pp. 99-12

Arnott, R., Davidsson, R. \& Pines, D. (1986), Housing Quality, Maintenance and Rehabilitation. The Review of Economic Studies, Vol. 50, No. 3, pp. 467-494

Arnott, R., Davidsson, R. \& Pines, D (1986), Spatial Aspects of Housing Quality, Density, and Maintenance. Journal of Urban Economics, vol 19, pp. 190-217

Arnott, R. \& Shevyakhova, E. (2014), Tenancy rent control and credible commitment in maintenance. CESIFO Working paper no 3608.

Blomé, G. (2011) Organizational and Economic Aspects of Housing Management in Deprived Areas, Dissertation. Dept of Real Estate and Construction Management, KTH- Royal Institute of Technology.

Blomé, G.(2013) Corporate social responsibility in housing management: is it profitable? Property Management Vol. 30 Nr: 4. S 351 - 361

Blomé, G \& Lind, H. (2012) Slumlords in the welfare state. International Journal of Housing Markets and Analysis, Vol. 5 Issue: 2, pp.196- 210

Borg, L. and Song, H. (2014). "Quality Change and Implications for Productivity Development: Housing Construction in Sweden 1990-2010." Journal of Construction Engineering and Management. 10.1061/(ASCE)CO.1943-7862.0000928, 05014014.

Boverket (2014) De allmännyttiga bostadsföretagens utveckling och roll på bostadsmarknaden 2012-2013. Karlskrona.

Ekelid, M. \& Lind, H. (1998) Transaktionskostnader och trohetsrabatter på bostadshyresmarknaden. Working Paper, Dept of Real Estate and Construction Management, KTH- Royal Institute of Technology.

Eklund, K. (2014), A funtioning housing market - a reform agenda. Bokriskommittén.

Elsinga, M. \& Lind, H. (2013) The Effect of EU-Legislation on Rental Systems in Sweden and the Netherlands, Housing Studies. DOI:10.1080/02673037.2013.803044

Högberg, L. (2011), Incentives for energy efficiency measures in post-war multi-family dwellings. Licentiate thesis. Dept of Real Estate and Construction Management, KTH- Royal Institute of Technology. 
Karlsson, P. (2013) Lönsamhet och råd i renoveringen av miljonprogrammet. Masters'thesis. Division of Building and Real Estate Economics, Royal Institute of Technology, Stockholm www.tallbergfoundation.org/Portals/0/Documents/Rapport\%20Energimyndigheten_2011.p df

Lind, H. (2012) Pricing principles and incentives for energy efficiency investments in multi-family rental housing: The case of Sweden. Energy Policy 49 (2012) 528-530

Lind, H. \& Lundström, S. (2008), Affären Gårdsten. Division of Building and Real Estate Economics, Royal Institute of Technology, Stockholm.

Lind. H., Annadotter, K., Björk, F., Högberg L. \& Klintberg. T. (2014) Sustainable renovation strategy in the Swedish Million Homes Programme: A case study. Working Paper, Dept of Real Estate and Construction Management. KTH.

Lind, H. och Muyingo, H. (2012) Critical reflections on the concept of maintenance. International Journal of Strategic Property Management, 16:2, s 105-114

Malpezzi, S.J. (1986), Rent control and housing market equilibrium : theory and evidence from Cairo, Egypt. George Washington Univ., Diss.

Mezgebu, D. (2014), Renoveringsstrategier på befintligt bostadsbestånd: Fyra fallstudier om allmännyttiga fastighetsbolag. Candidate thesis, Division of Building and Real Estate Economics, Royal Institute of Technology, Stockholm

O’Flaherty, B. (1998) Making Room. The Economics of Homelessness. Harvard University Press, Boston.

Olsen , E.O. (1988), What do economists know about the effect of rent contral on housing maintenance. Journal of Real Estate Finance and Economics, 1, 295-307.

Rosenthal, S. (2014) Are private markets and filtering a viable source of low-income housing? Estimates from a "Repeat Income" Model. American Economic Review, vol 104. Nr 2, s 687706.

SABO, (2009) Hem för miljoner: Förutsättningar för upprustning av rekordårens bostäder. Stockholm.

www.scb.se 